
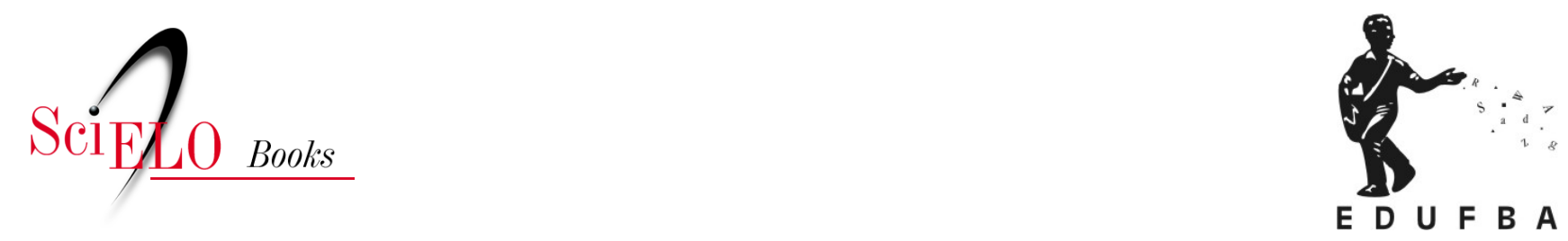

\title{
Posfácio \\ Rumo à práxis de um Hip-hop brasileiro feminista: uma introdução
}

\author{
Tanya L. Saunders
}

\section{SciELO Books / SciELO Livros / SciELO Libros}

SAUNDERS, T.L. Posfácio - Rumo à práxis de um Hip-hop brasileiro feminista: uma introdução. In: FREIRE, R.S. Hip-hop feminista? Convenções de gênero e feminismos no movimento Hip-hop soteropolitano [online]. Salvador: EDUFBA/NEIM, 2018. Bahianas collection, n. 20, pp. 199-209. ISBN: 978-85-232-1862-1. https://doi.org/10.7476/9788523218621.0009.

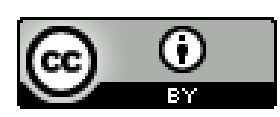

All the contents of this work, except where otherwise noted, is licensed under a Creative Commons Attribution $\underline{4.0 \text { International license. }}$

Todo o conteúdo deste trabalho, exceto quando houver ressalva, é publicado sob a licença Creative Commons Atribição 4.0. 


\title{
POSFÁCIO \\ Rumo à práxis de um Hip-hop brasileiro feminista: uma introdução ${ }^{99}$
}

\author{
Dra. Tanya L. Saunders \\ Professora Associada \\ Universidade da Flórida
}

A partir do momento em que abri este livro eu sabia que o Hip-hop feminista? Convenções de gênero e feminismos no movimento Hip-hop soteropolitano seria um livro importante. A autora, Rebeca Sobral, fez uma importante contribuição aos estudos do hip-hop, ao novo campo de estudos do hip-hop feminista, aos estudos feministas, aos estudos culturais e à teoria dos movimentos sociais. O livro começa com as questões centrais: há um hip-hop feminista de base jovem sediado na cidade de Salvador? Há hip hoppers feministas? Se assim for, o que é o hip-hop feminista e como ele influencia noções de gênero em Salvador/BA? Devo observar aqui que essas são as questões formais apresentadas pela autora em seu texto. O livro também envolve 
questões mais amplas sobre a práxis política e a negociação contínua do que constitui a "cidadania" no Brasil para pessoas normalmente excluídas dos processos políticos. Especificamente, o hip-hop, como um dos muitos movimentos sociais centrados na esfera cultural, desafia o que constitui um "cidadão" e que deve ser incluído em noções emergentes de cidadania no pós-ditadura no Brasil.

Muitas vezes, os movimentos sociais que ocorrem dentro da esfera cultural não são considerados movimentos sociais ou mesmo como sendo políticos. O que o livro de Sobral faz é intervir nesses discursos com o intuito de suscitar transformações em suas cabeças. Desenho dos principais estudiosos das Ciências Sociais no domínio da política cultural, a autora faz uma importante contribuição para os estudos acadêmicos emergentes e a pesquisa empírica sobre os movimentos sociais baseados nas artes. Ela usa esta pesquisa acadêmica para contextualizar um fenômeno social importante, o papel significativo que o hip-hop está exercendo no ativismo das mulheres em Salvador/BA, o tempo todo, considerando suas implicações a nível local e nacional.

O uso feito por Rebeca da etnografia e observação participante combinados com dados de entrevistas é guiado também pela metodologia feminista. Ou seja, no prazo de métodos de pesquisas feministas a estudiosa desenvolve uma pesquisa fundamentada empiricamente, a qual também busca superar preconceitos na pesquisa acadêmica, contribui para a mudança social, reflete a diversidade humana e reconhece a posição de pesquisadora. Sobral realiza tudo isso a tal ponto que também apresentou suas descobertas com as comunidades nas quais conduziu sua pesquisa.

Mais importante ainda, qualquer pesquisadora experiente entende que os métodos de pesquisa que uma estudiosa escolhe dependem da questão de pesquisa. Ou seja, se o objetivo da 
pesquisadora é compreender fenômenos sociais emergentes, então é importante ter tempo para observar e coletar dados sobre o referido fenômeno. Essa abordagem é importante para definir o terreno para futuras pesquisas em novas e importantes áreas de atividade social e política, uma vez que haverá um ponto de partida estabelecido para contextualização futura e comparação. A questão de pesquisa de Sobral é simples e importante: como esse fenômeno - especificamente ativismo hip-hop - tem se autoapresentado e como ele tem tido um impacto documentado sobre a sociedade e seus indivíduos? Como podemos avançar na análise desse fenômeno social? Os resultados de sua pesquisa renderam a documentação de um movimento social feminista que aborda questões centrais sobre cidadania, apresentadas por uma população muitas vezes excluída dos processos políticos estabelecidos. Além disso, e justamente por isso, a intervenção dessas ativistas ocorre na área da cultura.

A autora localiza a cena hip-hop em Salvador dentro de um movimento social nacional maior. Ela, então, situa esse movimento social nacional maior dentro da literatura sobre movimentos sociais de base cultural. Usando a literatura sobre movimentos sociais de base cultural, movimentos sociais feministas, dos jovens e dos movimentos sociais negros no Brasil, Sobral desafia a construção do que é considerado como a participação política legítima. Sobral desafia a ideia de que a cultura não é política, quando na verdade todos os movimentos sociais agem em uma política cultural. Ao situar o movimento Feminista Hip-hop no Brasil no nexo de vários movimentos sociais - negro, feminista e centrado de mulheres e movimentos sociais baseado em jovens -, ela cria o espaço necessário para começar a analisar a organização das mulheres dentro do hip-hop como um movimento social em Salvador, especificamente um movimento social feminista (ou de mulheres). A maneira com que Sobral trabalha essa importante 
intervenção permite futuros cientistas sociais serem capazes de estudar algo que soa claramente um sinal para examinar, como ela afirma, as mudanças geracionais, especificamente sobre como a política cultural é realizada por novas gerações de ativistas.

Após os primeiros capítulos situarem pesquisas e descobertas de Sobral, no final de três capítulos do texto a autora apresenta seu trabalho. No capítulo três, Sobral desenha sua experiência etnográfica participando de eventos de hip-hop em Salvador. Ela escreveu que não sabia o que esperar em primeiro lugar, se por um show ou outro tipo de evento artístico. O que ela percebeu foi que esses eventos eram realmente reuniões. Eles foram reuniões de conscientização centradas em capacitar mulheres jovens para participarem em eventos de hip-hop e/ou trabalharem para mudar a sociedade em geral.

Esses eventos tiveram títulos como "Lugar de mulher também é no hip-hop" e suas atividades desafiaram diretamente a natureza centrada no masculino do ativismo hip-hop para argumentar que as mulheres também são parte ativa e importante desse movimento e, num sentido mais amplo, da mudança social. Sobral extrai de seus dados de entrevistas a citação de uma rapper chamada Dina, que argumenta que os homens ocuparam espaço dentro do hip-hop, mas o seu acesso ao público é realmente baseado em uma questão cultural, e não é um resultado de algo particular do movimento.

Dina argumenta que as mulheres precisavam ser fortalecidas e prontas para encarar estes homens que detêm um processo cultural mais longo de dominar o espaço público e os movimentos políticos, e para dizer “Não é assim! Este espaço é nosso!”. Uma das intervenções que essas mulheres fazem é desafiar a estética, simbolicamente masculina, que tem sido comumente usada dentro do hip-hop. Isto é, a fim de serem levadas a sério, esperava-se que as mulheres usassem roupas masculinas. Rappers 
desafiaram isso como uma maneira de criar espaço para as mulheres também serem capazes de falar e serem levadas a sério como sujeitos femininos. Ao refletir sobre a diversidade de discursos do hip-hop nos Estados Unidos, Sobral também situa sua discussão sobre a diversidade das mulheres centrada nas perspectivas feministas dentro do movimento. Ela também destaca que o hip-hop soteropolitano (hip-hop da cidade de Salvador) é centrado em um nexo de mulheres e/ou ativismo feminista nacional conferido pela presença de artistas de hip-hop de várias cidades ao redor do país.

Uma questão central formulada pelas participantes (artistas e público em geral) em eventos do hip-hop é: o que é uma mulher, especificamente, e o que é uma mulher dentro do hip-hop? Através do envolvimento nessa questão, as artistas e o público em geral que participam nas conferências, simpósios e outros eventos organizados por artistas começam a desconstruir práticas de gênero e as formas em que as próprias mulheres, através de uma solidariedade expressa com os homens, continuam a reproduzir, inadvertidamente, muitos dos discursos que estavam trabalhando para mudar.

Sobral se concentra em intervenções das mulheres artistas nas quatro expressões artísticas chaves ou elementos do hip-hop: dança Break, MCing, DJing e graffiti. Todas as mulheres enfrentam diferentes formas de discriminação quando têm oportunidades para expor sua arte, pois são assumidas para não serem tão boas quanto os homens. No entanto, um dos aspectos interessantes do trabalho de Sobral é a comparação do modo como as mulheres e a feminilidade são entendidas em cada uma das formas de arte em que escolheram para expressar a sua energia criativa. Ela descobre que break-dancers, talvez, enfrentem o maior desafio de dança Break em si, pois contestam quase todos os aspectos das construções sociais de feminilidade, em especial, tornando a autonomia 
corporal das mulheres visíveis. O que Sobral fez aqui, através de sua análise perspicaz, foi articular uma importante área para pesquisas futuras: grande parte das pesquisas sobre as mulheres no hip-hop não consideram as políticas de gênero de cada um dos seus elementos e nivelam as experiências das mulheres que participam de cada uma dessas formas de arte. Ao considerar as experiências das mulheres dentro de cada uma das quatro expressões artísticas do hip-hop, podemos realmente saber mais sobre as experiências das mulheres de diversas perspectivas dentro do hip-hop em si.

Sobral localiza o hip-hop dentro de outras tradições culturais negras globais, como o funk. O hip-hop, como uma esfera pública racializada e uma cultura de música negra, surgiu como um espaço no qual a juventude negra pôde começar a se sentir habilitada, divertir-se, aprender e até mesmo cultivar uma autoestima mais forte em face de uma sociedade racista e sexista. As artistas entrevistadas sentiram que o hip-hop era uma empresa profundamente social, centrada na coletividade e na transformação social, além de um movimento que dialoga com quase todos os movimentos sociais no país. Isso é algo que eu também encontrei na minha pesquisa em Cuba intitulada Hip-hop Underground Cubano (Cuban Underground Hip-hop); como uma esfera pública racializada, também serviu como um nexo para os inúmeros movimentos sociais que ocorrem dentro da esfera cultural de Cuba. Isso não deveria surpreender como as vidas, experiências e interesses de pessoas afrodescendentes são diversas também.

Nos capítulos quatro e cinco Sobral faz suas mais fortes contribuições teóricas, extraídas de seus dados etnográficos, da observação participante e dados de entrevistas. No capítulo quatro, aborda os desafios discursivos das mulheres artistas do hip-hop quanto à forma e sobre como o gênero é entendido e experimentado, alternando desde a discussão sobre a família e a violência 
contra as mulheres, até a abordagem da diversidade sexual. A luta pela autonomia corporal das mulheres também tem sido um aspecto chave central das mulheres hip-hop ativistas.

No capítulo cinco, Sobral aborda a questão se há ou não realmente um hip-hop feminista. Nesse capítulo, ela apresenta a diversidade de teorias e autodefinições articuladas pelas artistas sobre seu ativismo como mulheres dentro do hip-hop. Variando de mulheres que se identificam com o feminismo e com o hip-hop feminista em particular, às mulheres que se distanciam do feminismo por causa da história do intelectualismo eurocêntrico, baseado em classe, que é associado ao termo. Não me deterei nos detalhes desse capítulo, porque acredito que aqui Sobral reúne todos os segmentos de seus textos e constrói um forte argumento para pensar se esse movimento centrado nas mulheres é um movimento social feminista. O que eu gostaria de fazer aqui, no entanto, é oferecer algumas considerações baseadas no campo emergente de estudos de hip-hop feministas nos Estados Unidos, como uma maneira de colocar o trabalho de Sobral e o trabalho dessas artivistas - ativistas que usam a arte para fazer suas intervenções políticas e trabalhar para a mudança social - em diálogo um com o outro.

Debates semelhantes sobre a política de identidades feministas surgiram entre as gerações mais jovens de mulheres que formam a primeira geração do hip-hop nos Estados Unidos. Após a comercialização do hip-hop, o lugar das mulheres nas letras de hip-hop e vídeos foi deslocado no imaginário para uma esmagadora maioria sexista e racista. As mulheres jovens que foram habilitadas pelo hip-hop e desenvolveram sua consciência política através dele foram taxadas por muitas feministas, particularmente feministas brancas americanas, como pessoas participando de sua própria opressão. 
Feminismo hip-hop como práxis feminista explícita surgiu na década de 1990, como um termo cunhado e teorizado por Joan Morgan em seu livro When Chickenheads Come Home to Roost (1999). O fato de que o feminismo hip-hop veio com o surgimento de estudos de hip-hop na década de 1990 não deve ser uma surpresa. As mulheres negras sempre foram uma parte em que desempenhou um papel fundamental nos movimentos sociais negros neste hemisfério - como Sobral argumenta em seu livro. Intelectuais negros, como Joan Morgan, escreveram que a precipitação da década de 1960 teve um impacto sobre a juventude negra que cresceu durante esse período; um efeito que se confunde com a forma do período de desindustrialização, condicionada ao ritmo impresso às ondas de globalização dos anos 1970 e 1980. Morgan (1999 apud SAUNDERS, 2016, p. 182) afirma:

Eu sou apoio, no entanto, por um feminismo que exige assumirmos a responsabilidade por nossas vidas. Na minha busca para encontrar um feminismo funcional para mim e minhas sistas - um que busca a capacitação espiritual, material, física, e nos níveis emocionais... Precisamos de uma voz como a nossa música - com sons de muitas vozes sobrepostas ${ }^{90}$ que injetem suas sensibilidades no velho e o transformem em algo novo, provocador e poderoso. E aquele cuja ocasional hipocrisia, contradições e banalidade nos garante, pelo menos, algumas divagações, forçando-nos a finalmente confrontar todos os sentimentos represados. [minha ênfase adicionada] ${ }^{91}$

O trabalho de Durham, Cooper e Morris, certamente, complementa a chamada. Morgan aponta para um feminismo que

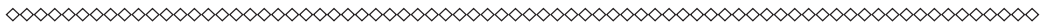

90 Sample é um termo utilizado na música, em música eletrônica, são "batidas" que significa inserir acordes de outras músicas - os DJs usam muito.

91 No original "I am down, however, for a feminism that demands we assume responsibility for our lives. In my quest to find a functional feminism for myself and my sistas - one that seeks empowerment on spiritual, material, physical, and emotional levels ... We need a voice like our music - one that samples and layers many voices, inject its sensibilities into the old and flips it into something new, provocative, and powerful. And one whose occasional hypocrisy, contradictions, and trite- ness guarantee us at least a few trips to the terror-dome, forcing us to finally confront what we'd all rather hide from. [my emphasis added]" 
reflete os materiais, experiências espirituais, físicas e emocionais de mulheres. Ao tomar mais de uma abordagem diaspórica para compreender o feminismo hip-hop, Durham, Cooper e Morris (2013, p. 722) definem o feminismo hip-hop como:

[A] articulação de uma específica geração de uma consciência feminista, epistemologia e política enraizada no trabalho pioneiro de várias gerações de feministas negras com sede nos Estados Unidos e em outros lugares na diáspora, mas com foco em questões e problemas que crescem fora das prerrogativas estéticas e políticas da cultura hip- hop.

A inclusão da "diáspora" é uma referência à Diáspora Africana, por isso eu acho que é tão importante colocar os artistas e o trabalho de Sobral em conversa com os estudos feministas de hip-hop estadunidenses: temos a possibilidade de fortalecer e reforçar o feminismo hip-hop como movimento Feminista do século XXI, trazendo as vozes da diáspora numa conversa mais ampla sobre a relação entre o hip-hop e as formas contemporâneas de práxis feminista negra diaspórica. Como Isoke (2013, p. 317) argumenta em sua discussão, a importância de

subjetividades translocais em enquadramento de análises de expressão política das mulheres negras globais...como locais específicos se relacionam entre si e ressoam uns com os outros como uma forma de cruzamento de fronteiras culturais e construção de pontes. ${ }^{92}$

Assim como feministas negras, pessoas negras não normativas e queer sempre fizeram parte da esfera pública negra. Muito parecido com o que os hip hoppers brasileiros artivistas estão fazendo, estudiosos como Adreanna Clay trouxeram visibilidade ao LGBT e

$\infty<\infty<\infty<\infty<\infty<\infty<\infty<\infty<\infty<\infty<\infty<\infty<\infty<\infty<\infty<\infty<\infty<\infty<\infty<\infty<\infty<\infty<\infty<\infty<\infty<\infty<\infty<\infty<\infty<\infty<\infty$

92 As Isoke (2013, p. 317) argues in her discussion of the importance of 'translocal subjectivities in framing analyses of global black women's political expression ... how specific locales relate to one another and resonate with one another as a form of cultural border crossing and bridgebuilding.' 
populações queer que também fazem parte da geração hip-hop. Em seu artigo "Like and Old Soul Record: Black Feminism, Queer Sexualiaty, and the Hip-Hop Generation" argumenta que a artista Me'Shell Ndegochello marca uma virada importante no feminismo negro e reflete as complexidades e contradições do feminismo hip-hop. (CLAY, 2008, p. 53)

O que eu gostaria de salientar aqui é o seguinte: desde a sua concepção, o feminismo nas Américas surgiu com a participação de mulheres negras. Nos Estados Unidos, por exemplo, dos discursos mais notáveis ao longo dessa história tem-se o discurso "Não sou mulher?", dado por Sojounet Troth (1797-1883), que nasceu na escravatura. Ela proferiu esse discurso em 1827, na Convenção das Mulheres em Akron, Ohio. Naquele momento, ela desafiou a concepção das mulheres feministas brancas sobre mulheres negras e igualdade das mulheres.

Uma coisa que eu gostaria ressaltar é que apesar do feminismo ser um termo usado para descrever o ativismo centrado nas mulheres, este, que existia antes desse termo ser cunhado, também as considera feministas. Assim, o termo "feminismo" não deve continuar a ser restringido à análise do ativismo centrado das mulheres brancas, pois nas Américas as mulheres negras foram certamente envolvidas no ativismo centrado das mulheres, a partir do momento em que chegaram a este hemisfério.

Além disso, as mulheres negras têm sido fundamentais na produção da história que o termo "feminismo" descreve. É por essa razão que o feminismo hip-hop é considerado uma forma de feminismo negro nos EUA, e a razão pela qual eu acho que é importante incluir as mulheres hip-hop ativistas como "hip-hop ativistas feministas”, mesmo se elas não se identificam como "feministas hip-hop". Ou melhor, mesmo que algumas mulheres nem sempre se identifiquem como feministas, é importante a pesquisa acadêmica que considera as intervenções teóricas centradas 
de mulheres ativistas - e aqui estou incluindo mulheres trans -, alegando o termo "hip-hop feminista", como uma forma de reconhecer a história formativa que as mulheres negras têm desempenhado no surgimento de várias conceituações de feminismo.

Bolsistas pesquisadoras devem continuar o trabalho de reconhecer a participação formativa das mulheres negras no surgimento da práxis feminista, como membros ativos de esferas públicas locais, nacionais e internacionais, mesmo se o ativismo das mulheres negras continuar a ser destituído por formas canônicas de estudos acadêmicos. No entanto, dado o trabalho inovador de estudiosas acadêmicas como Rebeca Sobral, fico animada ao saber que, independentemente de se decidir usar o termo "feminista", womanist ou outro termo ativista centrado nas mulheres, as intervenções políticas das mulheres negras pela transformação da sociedade em geral estão cada vez mais sendo documentadas dentro da pesquisa acadêmica, bem como recebem cada vez mais a consideração teórica e empírica que ela certamente merece. Uma realização refletida no hip-hop feminista. 